\title{
AFRODESCENDÊNCIA E AFRICANIDADE NA ESCOLA MUNICIPAL MONSENHOR MATEUS RUFINO, TERESINA/PI.
}

\author{
AFRODESCENDENCE AND AFRICANITY AT THE \\ MONSENHOR MATEUS RUFINO MUNICIPAL SCHOOL, \\ TERESINA / PI.
}

Tiago Souza de Jesus Secretaria de Estado da Educação do Ceará

Cleber Santos Vieira Universidade Federal de São Paulo / ABPN

\section{RESUMO}

O objetivo deste artigo é expor resultados de uma pesquisa de iniciação científica desenvolvida entre 2016 e 2017 na Universidade Federal de São Paulo. A investigação analisou as contribuições do Programa Mais Cultura nas Escolas (PMCE) para a implementação da Lei 10.639/o3, através do método de análise documental e entrevista semiestruturada de um projeto desenvolvido em uma escola de Teresina, Piauí. A pesquisa decorre de visitas realizadas em agosto de 2015 e fevereiro de 2016. No contexto, observamos que a capoeira contribuiu para que os estudantes adotassem uma postura de combate ao racismo antinegro, ao potencializar a relação entre território e escola, e aumento da autoestima dos estudantes negros. Neste sentido, o PMCE constitui-se como um mecanismo que facilita a entrada de mestres, mestras e demais fazedores de cultura no contexto escolar, propiciando o desenvolvimento de um processo pedagógico e educativo que promova tensão e o questionamento dos valores antes estabelecidos. Constatamos que a Lei 10.639/03, ao mesmo tempo em que embasa legalmente a luta da população negra por uma educação para as relações étnicas, exige mudanças nas práticas pedagógicas, de representação e comportamento e que, neste contexto abordado, tornou-se uma ferramenta legal para o desenvolvimento do citado projeto cultural.

Palavras-chave: Capoeira, Processo educativo, Território de maioria afrodescendente, Mais Cultura nas Escolas, Lei 10.639/03. 


\section{ABSTRACT}

The purpose of this article is to expose the results of a Undergraduate research developed between 2016 and 2017 at the Federal University of São Paulo. The investigation analyzed the contributions of the program "Mais Cultura nas Escolas" (PMCE) to the implementation of the law 10.639/o3, through the documentary analysis of a project developed in a school in Teresina, Piauí. The survey results from two visits carried out in August 2015 and February 2016. It turns out that, in the context of the information, we observed that Capoeira contributed to the students adopting a posture to combat anti-black racism, by enhancing the relationship between the territory of Afro-descendant majority and school, and increased self-esteem of black students. In this sense, the PMCE is a mechanism that introduces teachers and other culture makers to the school context, providing the development of a pedagogical and educational process that promotes tension and the questioning of values that were previously necessary. We note that Law 10.639/o3, at the same time that it legally supports the struggle of the black population for education in ethnic relations, requires changes in pedagogical practices, representation and behavior and that, in this approved context, it has become a ferocious legal framework for the development of the aforementioned cultural project.

Keywords: Capoeira, Educational process, Territory of Afro-descendant majority, More Culture in Schools, Law 10.639/03. 


\section{INTRODUÇÃO}

O Programa Mais Cultura nas Escolas (PMCE), ao longo de dois anos enveredou pelos caminhos de evidenciar que os mestres e mestras, bem como os demais fazedores de cultura há tempos batem à porta das escolas com intuito de desenvolver suas atividades nos espaços formais de ensino. Dentre eles, destaca-se a significativa parcela que atua nos estabelecimentos de ensino objetivando trabalhar a cultura afrodescendente bem como colocar em prática nesses estabelecimentos práticas pedagógicas antirracistas.

Este artigo é produto de uma pesquisa de iniciação científica desenvolvida no âmbito do CNPq, ao longo dos anos de 2016 e 2017. Os motivos nos quais fizeram dar início a pesquisa surgiram de uma experiência de campo ao longo do projeto "Mais Cultura nas Escolas: Promoção do diálogo entre iniciativas culturais e a educação formal”. Tal experiência refere-se ao impacto do depoimento de uma estudante negra de uma escola pública da cidade de Teresina-PI, ao relatar casos de racismo na escola e que após sua inserção no grupo de capoeira presente no ambiente escolar passou a combater os atos racistas que vinha sofrendo. Foram recolhidos depoimentos de estudantes negras participantes do projeto de capoeira na escola, bem como entrevistas com o Mestre proponente e responsável pelo desenvolvimento do projeto dentro da Instituição de Ensino e da gestora. É importante ressaltar que todos os trechos de entrevistas aqui destacados estão disponíveis nos formulários das pesquisas do Projeto Mais Cultura nas Escolas, que se encontram na Universidade Federal de São Paulo, campus Guarulhos.

É sintomático do sistema educacional brasileiro que os atos racistas de xingamento, chacotas e demais ações de fundo racista presentes no ambiente escolar não são vistas como racismo. A respeito, vale lembrar o referenciado estudo de Dagoberto José Fonseca em sua tese de doutoramento trabalhou a piada como expressão do preconceito étnico-racial e exclusão social (FONSECA, 1994). O Instituto Brasileiro de Geografia e Estatística (IBGE) aponta em seus dados que a evasão escolar 
é uma realidade que assola em sua maioria as pessoas de etnia negra e que, como agravante, as pessoas de etnia negra do sexo feminino estão na base dessa pirâmide ${ }^{1}$.

Neste sentido, "uma das causas frequentes, dentre muitas, da evasão, dos baixos aproveitamentos, ou, pelo menos, dos desconfortos e constrangimentos dos afrodescendentes nas escolas está relacionada com os afrodescendentes nas escolas está relacionada com os procedimentos de xingamentos, piadas e ações de fundo racistas" (CUNHA Jr., 2008, p. 229). Neste sentido, este trabalho buscou constatar a presença da capoeira na escola está intimamente ligada ao desempenho escolar dos estudantes, e que estes tiveram uma significativa mudança positiva, no sentido de que estes passaram a reconhecer-se enquanto membros dos espaços escolares, pelo fato de neste último agora se fazer presente um trabalho com temas pertinentes à realidade afrodescendente.

\section{1.o HISTÓRICO DOS MECANISMOS LEGAIS}

Precisamos compreender que o longo processo de luta da população afrodescendente não começou nas vésperas do ano de 2003, quando se deu a homologação da Lei 10.639/o3. Essa luta tem um lastro histórico que remonta o período da independência e é importante conectarmos as lutas históricas da população afrodescendente no que se refere às manifestações culturais, bem como a luta pela sobrevivência da capoeira em todo território nacional, sobretudo nos períodos de repressão e criminalização das culturas de origem africana.

\subsection{UM HISTÓRICO DE LUTA DA CAPOEIRA}

A capoeira, uma manifestação cultural afrodescendente, fundamentalmente de dança, luta, jogo, música, teatro e poesia, surge a partir do escravismo criminoso no

\footnotetext{
${ }^{1}$ A Rede Brasil Atual apresentou síntese de estudos realizado a partir de dados do IBGE de 2018 que a realidade da evasão escolar é sintomática da situação de exclusão étnica no sistema educacional brasileiro e assola, em sua maioria, mulheres negras. (REDE BRASIL ATUAL, 2019)
} 
Brasil. Tal como outras experiências re-elaboradas no contexto da diáspora africana nas Américas, observamos na capoeira uma associação entre ludicidade, disfarce e uma ligação mística com uma prática ritual.

Segundo Carlos Eugênio Soares, não é possível negar que em regiões africanas existem danças-lutas com características semelhantes às da capoeira e que podem ser a base da capoeira, tal como o $n$ `golo (SOARES, 2002, p. 145). Ao observarmos os processoscrime do século XIX, percebemos que estes nos mostram um panorama da origem dos africanos, ao expor que uma parcela significativa dos africanos presos e praticantes da capoeira eram originários da África Centro-Ocidental. (REIS, 1997, p. 87). Isso nos leva a constatar que a capoeira é uma reelaboração do que outrora era chamado de n'golo, o que a marca como africanidade brasileira. Para a intelectual negra Petronilha Beatriz Gonçalves e Silva, africanidades brasileira são reelaborações das culturas de origem africana. (SILVA, 2003)

Ao ser preso pela prática de capoeira, os escravizados eram considerados nocivos à sociedade como podemos observar nos processos-crime do período do século XIX analisados por Letícia Vidor Reis em: Capoeira como esporte negro: Angola e Regional (REIS, 1997), a perseguição já acontecia no Império. Ao consultarmos o Código Criminal do Império do Brasil de 1830, primeiro código normativo brasileiro, percebemos que não há uma referência direta ou uso do termo "capoeira”. O que acontece é que havia naquela sociedade o senso comum do capoeirista como "marginal, um vadio e sem profissão definida”, trecho enquadra o capoeira na tipologia presente no artigo no 295, que tratava da punição aos "vadios e mendigos" (REGO, 1968, 121).

Carlos Eugênio Líbano Soares, em sua obra A negrada instituição: os capoeiras na corte imperial (1850-1890) aponta as relações entre o Império e os capoeiras afirmando ser a Guarda Nacional um refúgio à capoeiragem (SOARES, 1999), demonstrando uma relação de interesses mútuos entre a Instituição nacional e as maltas de capoeira. Maltas, grosso modo, são grupos de capoeiras formados no período da Independência do Brasil e que tiveram efetiva participação durante a Guerra do Paraguai. Ao retornarem da guerra, tiveram importante participação na política, sobretudo atuando com partidos conservadores, que à época eram defensores do fim da escravidão. 
André Amaral de Toral nos mostra as entranhas da presença negra na Guerra do Paraguai, expondo um emaranhado de problemáticas. A presença de negros e pobres no Exército brasileiro não expõe o prestígio desses dois grupos na sociedade brasileira, mas sim que a Guerra era para os escravizados e pobres. "Como matar a los negros” é uma frase proferida pelo presidente do Paraguai que traduz a composição étnica da guarda nacional durante a Guerra de 1864-1870 (TORAL, 1995, p. 288).

Após a Proclamação da República é instituído em 11 de outubro de 1890 o Código Penal da República dos Estados Unidos do Brasil. No capítulo XIII intitulado "Dos vadios e capoeiras", artigo 402, definia como crime "fazer nas ruas e praças públicas exercícios de agilidade e destreza corporal conhecido pela denominação Capoeiragem”. Segundo Frederico José de Abreu, “a polícia perseguia um capoeirista como se persegue um cão danado" (ABREU, 1999, p.76). Porém, esta perseguição aos grupos de capoeira finda na década de 1930. Nessa década, o Brasil liderado por Getúlio Vargas tinha pretensões de transformar a capoeira em símbolo nacional, a partir das apresentações elaboradas por Manuel dos Reis Machado, o Mestre Bimba, responsável pela criação do novo estilo da capoeira, a chamada luta regional baiana. Essa era a retórica do corpo de Getúlio Vargas e no cenário baiano a Capoeira Regional.

Atualmente capoeira é difundida em todos os continentes, em mais de 150 países no mundo e conta com pelo menos três estilos: a capoeira angola, que tem seu maior expoente Mestre Pastinha, a capoeira Regional Baiana, que tem Mestre bimba como criador. E por fim, temos mais recente a capoeira contemporânea como elaboração de grupos como Cordão de Ouro, liderado por mestre Suassuna e Capoeira Abadá, como líder Mestre Camisa, dentre outros grupos igualmente tradicionais e em atuação no país e no mundo. Elevada à categoria de Patrimônio Cultural Imaterial brasileiro no ano de 2008, a capoeira hoje é uma fonte de conhecimento e autoconhecimento, dotada de várias possibilidades pedagógicas, culturais e patrimoniais.

\subsection{A LEI 10.639/03 COMO MECANISMO LEGAL}

A capoeira, uma manifestação cultural afrodescendente, é um importante instrumento para conhecimento da história e cultura afro-brasileira e africana e contribui fortemente para implementação Lei 10.639/03, que altera o conteúdo antes 
posto pela Lei de Diretrizes e Bases da Educação Nacional e determina obrigatório o ensino da história e cultura afro-brasileira e africana em todos os estabelecimentos de ensino formal do país. (BRASIL, 2003). A aprovação dela sinaliza uma vitória dos movimentos negros e diversos seguimentos da sociedade brasileira que estiveram e estão engajados na superação do racismo brasileiro. Porém, a promulgação não é suficiente e desde então, intensificaram-se os movimentos para sua implementação.

Visando orientar, o Conselho Nacional de Educação lança o parecer CNE/CP no . 03, 10 de março de 2004 que, dentre outras coisas, evidencia os motivos históricos que levaram à aprovação da citada lei 10.639/03. Motivos esses que apontam para a necessidade de reconhecimento da população Afrodescendente, bem como reparações das desigualdades históricas.

Entendemos reconhecimento como "justiça e iguais direitos sociais, civis, culturais e econômicos, bem como valorização da diversidade daquilo que distingue os negros dos outros grupos que compõem a população brasileira" (BRASIL, 2004, p. 03). Isso implica, segundo o Parecer, em uma mudança estrutural na sociedade brasileira, transformando os "discursos, raciocínios, lógicas, gestos, posturas, modo de tratar as pessoas negras" (BRASIL, 2004, p. 3).

\section{O PROGRAMA MAIS CULTURA NAS ESCOLAS: HISTÓRICO}

Antes de falarmos do PMCE, é importante destacarmos que o projeto de capoeira apresentado ao PMCE tem um lastro histórico que iniciou em 2007 nos programas Escola Aberta e Acelera Brasil, na ocasião, estagiário da Escola Municipal Governador Chagas Rodrigues, no loteamento Francisca Trindade, localizado no bairro Santa Maria da Codipi, em Teresina-PI. O mestre conta em entrevista concedido em agosto de 2015 que nessa situação realizou uma inserção dos estudantes à capoeira, apresentando conceitos e fundamentos básicos. Nesse contexto de entrevista, o mestre estava recebendo a visita de pesquisadores do PMCE em sua escola em Teresina. Veio a receber também uma segunda visita do mesmo grupo, com intuito de fornecer 
depoimentos para elaboração de um curta-metragem organizado pelo Ministério da Cultura em Fevereiro de 2016. ${ }^{2}$

O Programa Mais Educação (PME) em 2012 também foi um dos programas de significativa importância, segundo o mestre. Este tem como escopo construir uma agenda de educação integral no país. Para que essa agenda seja construída, é necessária uma série de ações em torno do objetivo. Um dele é a mudança de concepção acerca da educação, da pedagogia, dos processos pedagógicos e, sobretudo, da diversidade cultural existente no país. Essas miríades de conceitos são importantes para elaboração de projetos que venham acrescentar experiências em torno da construção de uma agenda de educação integral.

O processo educativo, portanto, ultrapassa os muros da escola e da sala de aula e percorre toda a comunidade, envolve a cultura local. Mestre Fu Pagu3, atento à proposta do Programa, resolveu aprimorar seus conhecimentos e práticas acerca da capoeira, elaborando um projeto socioeducativo que foi desenvolvido aos sábados na Escola Municipal Monsenhor Mateus Rufino. Esta seria a primeira vez que ele desenvolveria um projeto nesta escola.

O PMCE, portanto, tem a finalidade de fomentar propostas e experiências culturais já em curso nas comunidades locais e nos mais diversos múltiplos territórios (BRASIL, 2013, p. 3). Por meio da Resolução no 30, de 3 de agosto de 2012 (FNDE, 2012), cada escola inscrita e aprovada recebeu até 22 mil reais para desenvolver o projeto conjuntamente com uma iniciativa cultural parceira escolhida para desenvolver as atividades culturais. O Ministério da Cultura recebeu, ao todo, entre os anos de 2013 e 2014, 14.061 projetos dos quais foram selecionados 5.069 em todo o país. As escolas iniciaram suas atividades no segundo semestre de 2014 (BRASIL, 2015).

Em 2013 foi lançado um curta-metragem de apresentação do Programa Mais Cultura nas Escolas, que foi amplamente divulgado entre os grupos culturais, instituições de ensino e secretarias de educação. O curta-metragem foi elaborado pelo

\footnotetext{
${ }^{2} \mathrm{O}$ teaser do média-metragem produzido pelo Ministério da Cultura em parceria com o Ministério da Educação pode ser consultado através do link a seguir: https://vimeo.com/177157301

${ }^{3}$ Cristiano Soares será apresentado em breve, porém, vale ressaltar que vamos nos referir à Cristiano pelo seu nome de batismo na Capoeira, que é Mestre Fu Pagu.
} 
Ministério da Cultura em parceria com o Ministério da Educação. Neste, podemos perceber que a intenção do Programa é educar com a cultura local do bairro, fomentando possibilidades de aprendizado que cruzam com interesses das propostas de Educação Integral no país e viabilizando a inserção de protagonistas antes pouco visto no ambiente do ensino formal: mestres e mestras da cultura, artistas e demais fazedores de cultura. 4

Segundo a cartilha do PMCE lançado em 26 de julho de 2014, é previsto o monitoramento das atividades desenvolvidas nas escolas contempladas, com a finalidade de registrar dados necessários para avaliações do impacto da política pública na sociedade (BRASIL, 2014, p. 12). Desta ideia surge o projeto Mais Cultura nas Escolas: Promoção do diálogo entre iniciativas culturais e a educação formal, uma parceria firmada entre o Ministério da Educação (MEC) e a Universidade Federal de São Paulo (UNIFESP), campus Guarulhos5.

O Piauí constituiu-se como um dos Estados que apresentou um volume razoável $^{6}$ de projetos aprovados, 127 no total. Teresina foi a única cidade piauiense que recebeu os pesquisadores. Em uma visita de três dias, foram visitadas cinco escolas públicas distribuídas em todas as regiões da capital piauiense. As visitas a Teresina foram consentidas e acompanhadas pela Secretaria Municipal de Educação (SEMEC).

Dentre essas, está a Escola Monsenhor Mateus Rufino, instituição municipal pública, localizada em um território de maioria afrodescendente de nome Parque Rodoviária. Para Henrique Cunha Junior "a cultura de um território de maioria afrodescendente pode ser traduzida pelos conjuntos dos repertórios culturais presentes neste espaço geográfico" (CUNHA JUNIOR, 2007, p. 72). Esses territórios

\footnotetext{
${ }^{4} \mathrm{O}$ curta-metragem de apresentação da proposta do Programa pode ser consultado no link a seguir: https://www.dailymotion.com/video/x3629ot

${ }^{5}$ Salientamos que a pesquisa de campo realizada na data de 01 de agosto de 2015 foi autorizada pelo Comitê de Ética e Pesquisa (CEP) por meio do Parecer 1.009.318, de 01/04/2015 e os dados, segundo a supervisão do Prof. Dr. André Luiz Pereira Tavares, podem ser utilizados para pesquisa de campo e estão disponíveis na UNIFESP campus Guarulhos. Já a visitação realizada em 11 e 12 de 2016 com fins de captação de imagens de audiovisual para o curta-metragem contratado pelo Ministério da Cultura, teve sua divulgação no Fórum de Educação Popular de 2016 (FREPOP/2016), em Recife-PE. No qual o pesquisador autor do presente estudo fez parte da elaboração e da edição do resultado.

${ }^{6}$ Considera-se volume razoável de projetos os estados que tiveram aprovados entre 100 e 200 projetos.
} 
são "espaços urbanos em que encontramos outros grupos sociais de origens históricas e culturais diversas, mas encontra-se a população afrodescendente como maioria, sendo esta a que determina a dinâmica cultural e social desses territórios" (CUNHA JUNIOR, 2007, p. 71).

\section{A CAPOEIRA, A ESCOLA E O BAIRRO: UM DIÁLOGO NECESSÁRIO}

As constatações realizadas por Mestre Fu Pagu em relação ao território em que a escola estava inserida detém uma especial importância no processo de ensino e aprendizado, sobretudo do próprio mestre. Tal constatação permite ao mestre ter um olhar ampliado em relação aos processos educativos que envolvem o processo de aprendizado dos estudantes. Por processo educativo, entendemos algo mais amplo do que o ensino em instituições especializadas (ITURRA, 1994, p. 40).

O racismo estrutural no Brasil é naturalizado e permeia o interior das relações sociais e institucionais. Nessa esteira, lugar social historicamente atribuído ao negro passa a ser questionado pela noção de "pertencimento afro", produzindo um confronto (GOMES, 2012, p. 107) que afirma e valoriza a "importância da matriz africana para a constituição da pessoa” (ALVES, 2015, p. 36 apud SILVA \& PETIT, 2011, p. 87).

A iniciativa cultural parceira chama-se Cristiano Soares, é mestre de capoeira, monitor do Programa Mais Educação, atuou em escolas através de vários programas já citados. Mestre Fu Pagu foi representante do Brasil no Projeto de Cooperação TécnicoProfissional entre Brasil e África, promovendo encontros de capoeira nos países São Tomé e Príncipe e Guiné-Bissau. Atualmente é estudante de Educação Física em uma universidade de Teresina.

$\mathrm{O}$ projeto que Mestre $\mathrm{Fu}$ Pagu desenvolveu na escola, abordou a cultura afrodescendente e suas influências na sociedade e cultura brasileira, por meio de manifestações culturais como a capoeira e o maculelê. Sob esse prisma, buscaram resgatar as tradições culturais afrodescendentes. O mestre afirma buscar "Promover nos estudantes e na comunidade o reconhecimento da importância da interseção da história e da cultura africana com a história e a cultura brasileira para transformar as relações entre os diversos grupos étnico-raciais que formam a comunidade em que a 
escola está inserida"7. Abaixo observamos trechos da gravação do projeto, em que os estudantes estão representando a pesca entre os capoeiristas.

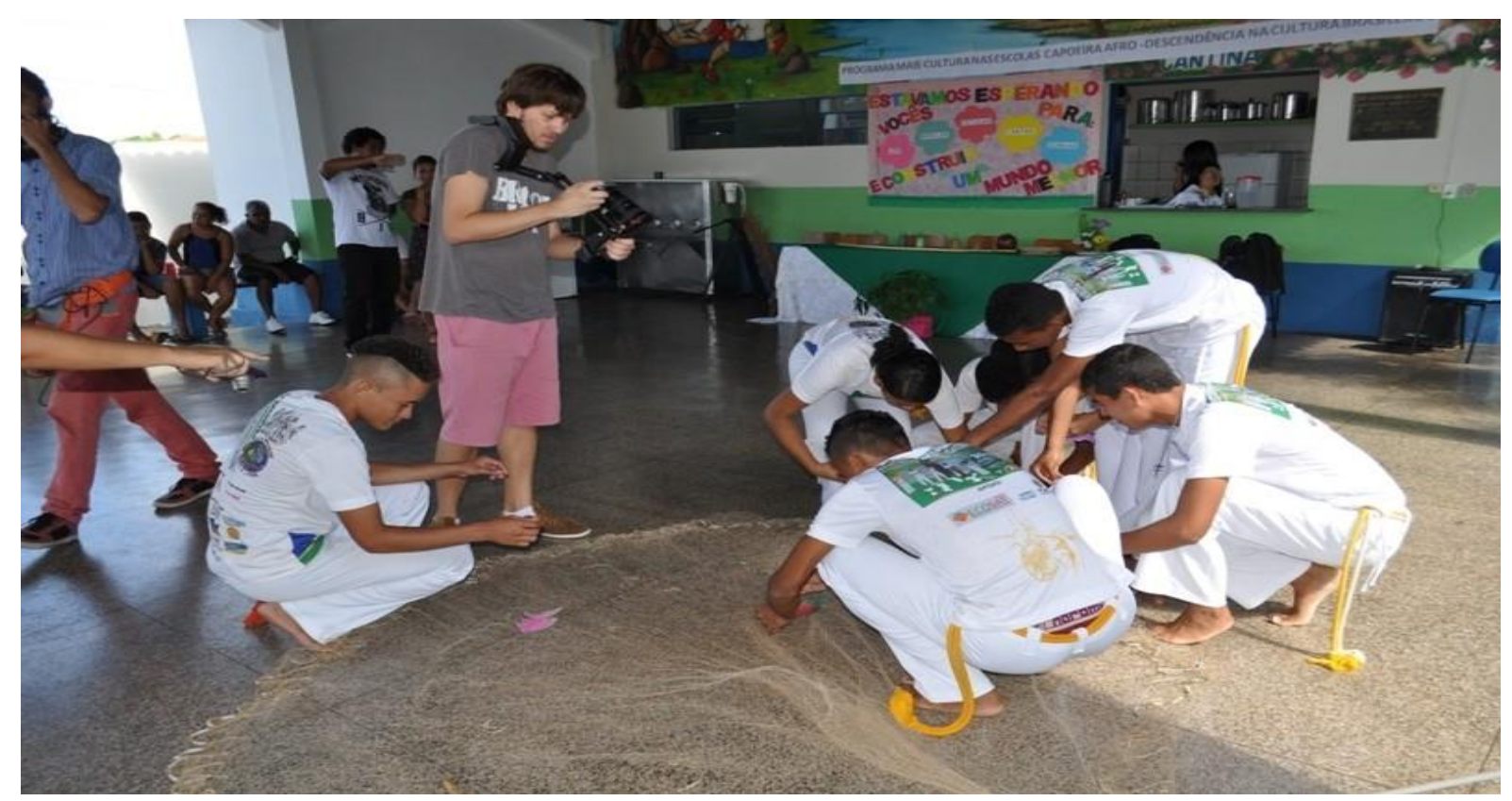

Imagem 1: Estudantes da escola fazendo a representação da pesca, prática cotidiana presente também entre os capoeiristas. Fonte: Arquivo pessoal: 2016.

Percebemos que existe uma proposta de ação e tomada de consciência por parte do mestre. Paulo Freire assevera que "somente os seres que refletir sobre sua própria limitação são capazes de libertar-se desde, porém, que sua reflexão não se perca numa vaguidade descomprometida, mas se dê no exercício da ação transformadora da realidade condicionante" (FREIRE, 2007, p. 78).

Por meio de leituras e pesquisas realizadas na comunidade "com os moradores mais velhos”, mestre Fu Pagu, em uma ação e reflexão, juntamente com as crianças busca evidenciar elementos da cultura africana, bem como "a cor da população do entorno em seu alto percentual de pertencentes a matriz afro-brasileira”. Essa importante perspectiva do mestre encara, assim como para Freire (2007), a educação como um processo e inclui, assim também como Cunha Junior a consciência da localidade e do seu entorno no processo formador dos estudantes envolvidos, uma vez que as relações, sobretudo entre os afrodescendentes se dão a partir dos territórios. (CUNHA JUNIOR, 2001)

\footnotetext{
${ }^{7}$ Trecho retirado do projeto apresentado ao Programa Mais Cultura nas Escolas.
} 
Quando a pesquisadora Sandra Petit afirma que "falta perceber melhor que tipo de saberes estão envolvidos nas diversas manifestações culturais brasileiras” (PETIT, 2015, p. 111), quer dizer que existem potencialidades presentes em manifestações como a capoeira, que é importante ser percebido e ressaltado no processo pedagógico. A estudante $\mathrm{n}^{0} 1$ de 13 anos foi perguntada sobre o projeto, especificamente se ela gostou do projeto de capoeira. Ela responde que "Sim, porque me ajudou bastante dentro da escola principalmente na aprendizagem me ajudou muito a superar minha timidez".

Foi perguntado a estudante se ela acredita que a escola deva continuar oferecendo mais atividades culturais. A estudante afirma que sim, e conclui justificando que "Essas atividades podem ajudar muitos alunos na questão da aprendizagem e respeito". A estudante $\mathrm{n}^{\mathrm{O}} 2$ de 13 anos de idade afirma que "muita coisa mudou. Hoje eu tenho mais respeito, principalmente na minha família. Agora eles veem que eu gosto de vim para a escola e isso é bom”, finaliza a estudante.

A estudante $\mathrm{n}^{\mathrm{o}} 1$ afirma que passou a ter boas notas em História e Artes. Perguntada do porquê do aumento das notas, ela afirma que "através da capoeira, pude aprender muita coisa que tinha a ver com o que era aprendido na sala de aula. A arte africana me ajudou muito a aprender mais sobre arte. E toda vez que a gente estudava história da capoeira eu conseguia entender melhor a história de muitas coisas”.

Além da pesquisa intitulada "a cor da comunidade", mestre $\mathrm{Fu}$ Pagu desenvolveu outra pesquisa com os estudantes sobre a história da capoeira e dos grandes mestres: "criamos um grupo no WhatsApp que circulava apenas informações sobre as oficinas e pesquisas realizadas pelos próprios estudantes em seus celulares". O grupo mantinha fluxo contínuo de mensagens instantâneas, havendo conversas diárias e compartilhamentos de fontes de informação sobre a capoeira entre os estudantes e o mestre: "Um estudante achou um link com várias histórias de Mestre Pastinha e aí resolveu compartilhar no grupo. Todos nós tivemos acesso”.

Além do uso da internet e aplicativos de mensagens instantânea para difusão do conhecimento no grupo, mestre Fu Pagu afirma que as pesquisas também aconteciam na única biblioteca da região, que ficava em outro bairro: 


\begin{abstract}
"Nós tínhamos que nos deslocar para lá, custava dinheiro que não tinha, mas fazíamos aquele esforço. Sempre na parceria com a diretora que nos apoiou do início ao fim. Nós sabíamos que os estudantes gostavam de ir lá. Percebemos também que a biblioteca era um lugar desconhecido por muitos deles, mesmo aqueles que moram aqui desde que nasceram desconhecem esse espaço. Daí a importância de levá-los para conhecer e se apropriar desse espaço público”. (Mestre Fu Pagu, entrevista, 2016)
\end{abstract}

Os saberes tradicionais da capoeira e presentes dentro da escola qualificaram o processo pedagógico, uma vez que a autoestima dos estudantes juntamente com um crescimento da vontade de estudar contribuiu fortemente para um melhor desempenho desses estudantes assistidos pelo Programa. A diretora da escola afirma que "a nota de muitos melhorou, alguns professores chegaram a me contar que alguns deles mudaram muito o comportamento dentro da sala de aula”.

A gestora conta também que não houve participação de qualquer professor da escola no projeto de capoeira. Houve apresentações e convites feitos, porém, não houve sucesso na tentativa de trazê-los para o projeto. Somente o mestre o executou. O silêncio docente diante da questão étnica não presente na sala de aula, segundo Nilma Lino Gomes, não advém da falta de conhecimento, mas sim de um diálogo com o mito da democracia racial no contexto do racismo ambíguo brasileiro (GOMES, 2012).

As relações, consentidas ou não, entre os denominados brancos e negros, foram capazes, segundo a ideologia da mestiçagem, de pulverizar os negros, criando uma nova categoria, o mestiço. Somos todos iguais, segundo esta ideologia (MUNANGA, 2008), porém, a mestiçagem não mestiçou a nossa conta bancária, (CUNHA JUNIOR, 2007, p. 62) muito menos os espaços habitados e as estruturas de poder.

A Lei 10.639/o3 representa a introdução de novos conteúdos e com isso propicia como uma mudança cultural e política no campo curricular e epistemológico - o que pode romper com o silêncio e descortinar outros rituais pedagógicos. É importante ressaltar que esses novos conteúdos com a Lei tornam-se obrigatórios, porém, tais conteúdos já vinham sendo trabalhados por educadores alinhados com a luta do povo negro e que reivindicaram por décadas a obrigatoriedade e que o Estado desse a devida relevância para tais conteúdos em sua base curricular. A Lei promove um diálogo 
intercultural emancipatório no interior da escola que considera a existência do "outro", produzindo tensões, conflitos e divergências. Porém, não há nenhuma harmonia nas transformações sociais (GOMES, 2012).

Perguntada se o comportamento dos estudantes havia mudado, a estudante $\mathrm{n}^{\mathrm{o}}$ 2 afirmou que "Sim, eu percebi que andam acontecendo menos brigas. Antes eu era chamada coisas que me deixava triste como por exemplo de cabelo duro, mas hoje isso não acontece mais, porque eu não deixo. Eu aprendi que sou igual a todo mundo e se eles me chamarem assim de novo eu vou para cima deles". Respondeu com risos. ${ }^{8}$

\section{UMA BREVE DISCUSSÃO}

Os dados coletados no recorte espacial apresentado evidenciam que o desempenho escolar parece estar influenciado pela maneira como a criança vê a si mesma, muitas vezes dentro de suas limitações e dificuldades de socialização que acabam reforçadas pela falta de atividades que contribuam para superação desses problemas.

Nessa perspectiva, percebe-se que as oficinas de capoeira desenvolvidas a partir do PMCE pelo Mestre Fu Pagu têm elevado a autoestima dos estudantes de forma positiva através das atividades, que buscam resgatar a identidade étnica, promovendo o contato e valorização com a diversidade cultural. Dessa forma, enorme é a importância de uma educação de qualidade aliada à cultura para o desenvolvimento dos estudantes.

\footnotetext{
${ }^{8}$ A estudante utilizou-se de figura de linguagem ao afirmar que "vai para cima dos estudantes" que agem com racismo contra ela, uma vez que a gestora entrevista afirmou não ter acontecido qualquer caso de agressão física por iniciativa das estudantes negras beneficiadas. Ainda que ocorressem casos de agressão física, para Malcolm X (1963), este ato não se configura como violência, mas sim como autodefesa.
} 


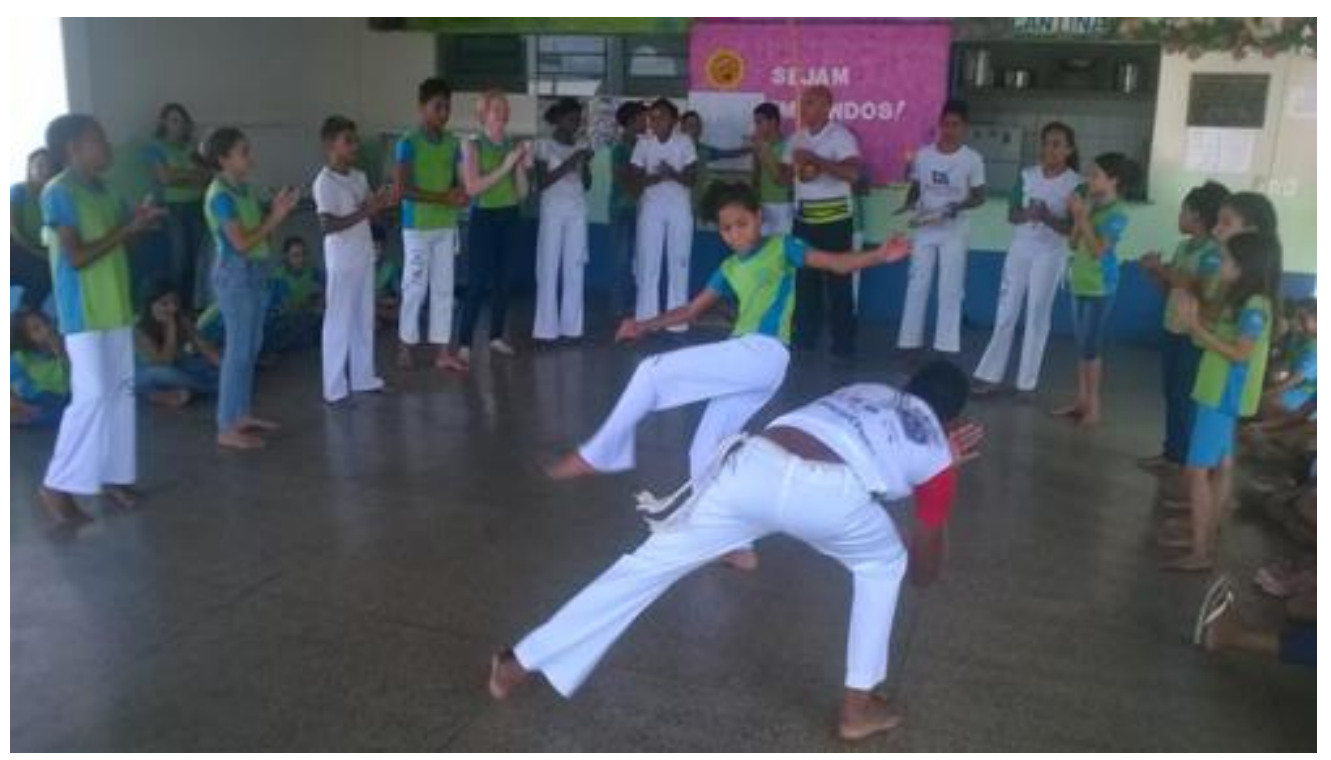

Imagem 2: estudantes jogando capoeira em visita de pesquisadores à escola. 2015 . Arquivo pessoal.

Acima observamos estudantes jogando capoeira durante a segunda visita dos pesquisadores, na ocasião para elaboração de um curta-metragem ${ }^{9}$ para divulgação dos resultados do projeto cultural de capoeira. A pesquisa de campo com os moradores mais idosos aproximou a comunidade da escola, uma vez que seus estudantes retornaram para as suas casas e dos vizinhos não para dialogar sobre o cotidiano, ainda que importante, mas para sistematizar tudo que já havia sido conversado ao longo de suas experiências. Isso promove outro olhar da comunidade sobre a própria escola e seus estudantes. Os muros que separam a escola da comunidade deixam de existir.

\section{ALGUMAS CONCLUSÕES}

Observou-se na pesquisa realizada que com as iniciativas culturais parceiras e as escolas desenvolveram atividades culturais que potencializaram a relação entre território e escola, relação que contribuiu para o aumento da autoestima dos estudantes beneficiados, bem como o combate ao racismo, sobretudo na escola que foi nosso objeto de pesquisa, como foi observado no relato de uma das estudantes entrevistadas.

\footnotetext{
${ }^{9} \mathrm{O}$ teaser do curta-metragem está disponível em uma plataforma de vídeos chamada Vimeo e pode ser acessado por meio do link: https://vimeo.com/177157301
} 
A interlocução entre experiências culturais dos territórios de maioria afrodescendentes e as escolas potencializa a educação formal, fazendo com que os estudantes sintam-se pertencentes da escola e reconheçam-se enquanto sujeitos dos processos educativos, o que atesta a possibilidade dos (as) estudantes envolvidos no projeto de "ser mais". ${ }^{10} \mathrm{O}$ contrário disso, conclui Freire, é a desumanização.

O Programa Mais Cultura nas Escolas se mostrou uma política pública capaz de viabilizar o acesso de mestres e mestras no contexto da educação formal. Essa possibilidade reforça um entendimento de educação que ultrapassa os muros da escola e habita os espaços públicos do entorno da instituição de ensino. Compreende as manifestações culturais afrodescendentes capazes de quebrar epistemologias distantes da realidade de estudantes de bairros negros.

\section{Referências}

ALVES, Maria Kellynia Farias. Resistência negra no círculo de cultura sociopoética: pretagogia e produção didática para implementação da lei 10.639/o3 no PROJOVEM urbano. 2015. 159 f. Dissertação (Mestrado em Educação) - Faculdade de Educação Universidade Federal do Ceará. Fortaleza, 2015.

BRASIL. Alteração da Lei 9.394 de 20 de dezembro de 1996. Lei ${ }^{0}$. 10.639, 9 de janeiro de 2003.

. Ministério da Educação. Conselho Nacional de Educação, Parecer $\overline{\mathrm{CNE} / \mathrm{CP} \mathrm{n}^{\mathrm{o}}}$. 03, 10 de março de 2004.

. Ministério da Educação. Educação e Cultura debatem ações conjuntas. 2015. Disponível online por meio do sítio: http://portal.mec.gov.br/component/tags/tag/35860 acesso em 20/o8/2020.

CUNHA JUNIOR, Henrique. Africanidade, afrodescendência e educação. Fortaleza: Revista Educação em Debate, ano 23, vol. 2 - número 42, 2001.

10 FREIRE. Paulo. Paulo Freire - Vocação do Ser Mais. Disponível online no You Tube. https://www.youtube.com/watch?v=DO8012ByrF8 acesso em 15/01/2018. 
. Espaço Urbano e Afrodescendência. In: CUNHA JUNIOR,

Henrique e RAMOS Maria Estela Rocha. (Orgs) Espaço Urbano e afrodescendência. Estudo da espacialidade negra urbana para o debate das políticas públicas. Fortaleza: UFC Edições, 2007. 206 p.

CUNHA JUNIOR, Henrique; GOMES, Ana Beatriz Souza. Educação e Afrodescendência no Brasil. Fortaleza: UFC Edições, 2008. 287 p.

FONSECA, Dagoberto José. A piada-discurso sutil da exclusão: um estudo do risível no racismo a brasileira. 1994. Tese de Doutorado. Pontifícia Universidade Católica de São Paulo.

FREIRE, Paulo. Ação cultural para liberdade e outros escritos. São Paulo: Paz e terra. 2007, $12^{\text {a }}$ Ed.

Paulo Freire - Vocação do Ser Mais. Entrevista concedida em 1997. Disponível: https://www.youtube.com/watch?v=DO8O12ByrF8 acesso em 15/01/2018.

GOMES, Nilma Lino. Relações Étnico-Raciais, Educação e Descolonização dos Currículos. Currículo sem Fronteiras, v. 12, p. 98-109, 2012.

ITURRA, Raul (1994) “O processo educativo: ensino e aprendizagem?” In Revista Educação, Sociedade \& Culturas, ${ }^{0}{ }^{1}$, Afrontamento, Porto, (pp.29-50).

MUNANGA, Kabengele. Rediscutindo a mestiçagem no Brasil: identidade nacional versus identidade negra. 3ed. Belo Horizonte: Autêntica, 2008.

PETIT, Sandra Haydée. Pretagogia: Pertencimento, Corpo-Dança Afroancestral e Tradição Oral Africana na Formação de Professores e Professoras - contribuições do legado africano para a implementação da Lei 10.639/2003. Fortaleza: EdUECE, 2015.

REDE BRASIL ATUAL. Evasão escolar é maior entre jovens negros. 'É a violência do racismo'. São Paulo: 2019. Matéria disponível online no sítio:

<https://www.redebrasilatual.com.br/educacao/2019/o9/evasao-escolar-e-maiorentre-jovens-negros-e-a-violencia-do-racismo/> acesso em 20/o8/2020.

RÊGO, Waldeloir (1968). Capoeira Angola - Ensaio Sócio-Etnográfico. Salvador: Editora Itapuã. 
REIS, Leticia Vidor de S. "Capoeira como esporte negro: Angola e Regional". In: O mundo de pernas para o ar. São Paulo Publisher Brasil/FAPESP, 1997.

SOARES, Carlos Eugênio L. "De Cabindas a Crioulos: as nações de capoeira". A capoeira escrava e outras tradições rebeldes no Rio de Janeiro. (1808-1850), São Paulo, Ed. da UNICAMP, 2002, pp 73-163.

SILVA, Petronilha Beatriz Gonçalves e. Africanidades: esclarecendo significados e definindo procedimentos pedagógicos. In: Revista do Professor. Porto Alegre, v.19, $\mathrm{n}^{0} 73 /$ mar.2003. p.26-30.

TORAL, André Amaral de. A participação dos negros escravos na guerra do Paraguai. Estud. av., São Paulo , v. 9, n. 24, p. 287-296, ago. 1995 • Disponível em <http://www.scielo.br/scielo.php?script=sci_arttext\&pid=So10340141995000200015\&lng=pt\&nrm=iso >. acessos em 22 ago. 2020.

\section{Sobre os autores}

Tiago Souza de Jesus: Bacharel (2016) e licenciado (2017) em História pela Universidade Federal de São Paulo. Especialista em História e Cultura Afro-brasileira e africana pela Universidade Federal de Goiás. Ex-avaliador de políticas públicas (MinC/MEC, 2014-2016). Coordenador do NEABI EEMTI Casimiro Leite de Oliveira. Professor na SEDUC-CE. E-mail para contato com autor: tiagounifesp@gmail.com

Cleber Santos Vieira: Possui Graduação (1997) e Mestrado (2001) em História pela UNESP. Doutorado em Educação pela Universidade de São Paulo (2008). Professor doutor na Universidade Federal de São Paulo e Presidente da APBN. E-mail: clebersvieira@yahoo.com.br 